\title{
Absolute Instantaneous Optimal Control Performance Index for Active Vibration Control of Structures under Seismic Excitation
}

\author{
Arcan Yanik (iD \\ Department of Civil Engineering, Istanbul Technical University, Istanbul 34469, Turkey \\ Correspondence should be addressed to Arcan Yanik; yanikar@itu.edu.tr
}

Received 19 July 2019; Accepted 22 October 2019; Published 12 November 2019

Academic Editor: Stefano Marchesiello

Copyright (C) 2019 Arcan Yanik. This is an open access article distributed under the Creative Commons Attribution License, which permits unrestricted use, distribution, and reproduction in any medium, provided the original work is properly cited.

In this paper, an instantaneous optimal control performance index for active control of structures under seismic excitation is analytically proposed. Absolute velocity and absolute displacement terms are implemented to the conventional state vector terms and eventually to the resulting performance index expression. The seismic response reduction effectiveness of the proposed performance index is compared with the linear quadratic regulator control (LQR). For numerical verification of the performance index, an eight-story shear building with a fully active tendon controller system under unidirectional earthquake is considered as the first example. For a more complex model, a three-dimensional tier building under the effect of bidirectional earthquakes is selected as second numerical example. Unidirectional near fault and bidirectional near fault earthquakes are used in the simulations. The control energy demand of each control method is also considered in the comparison. It is obtained from numerical simulations that the proposed performance index is as effective as LQR in attenuating structural vibrations. However, the resulting performance index does not require a priori knowledge of the seismic excitation like the LQR. The nonlinear Riccati matrix equation solution of the LQR is not required in the proposed performance index as well.

\section{Introduction}

Active control has been an interesting topic of research for seismic mitigation of structures since smart control devices into structures were first implemented by Yao [1]. An active control device includes a real-time controller and a power supply, and it is integrated with control computers and sensors which are implemented to the structure. An active control algorithm should be used while operating an active controller device. The active control device could either be an active control actuator, active tendon controller, or active mass damper. There are many interesting studies on new active control methods and new active control algorithms in the last years [2-10]. Shen et al. [2] investigated three control algorithms for active vibration control of the sting in wind tunnel. These algorithms were Classical Proportional and Derivative Algorithm, Artificial Neural Network Proportional Integral Derivative, and Linear Quadratic Regulator (LQR) Optimal Control Algorithm [2]. Active structural control was applied to an idealized two-span concrete highway bridge structure in [3]. They idealized the continuous girder bridge as a two degrees of freedom system [3]. A decentralized scheme for active noise control from a game-theoretical perspective was studied by Quintana and Diego [4]; they formalized the Nash equilibrium in the interaction between the controllers in their interesting study. A force feedback-based control method for active tuned mass dampers was described by Wang and Yun [5]. Direct velocity feedback was implemented to their method [5]. A new performance index for active vibration control of threedimensional structures was presented numerically by Yanik et al. [6]. The problem of designing a state-feedback controller with both active structural control and passive base isolation was considered analytically/numerically by Miyamoto et al. [7]. A simple active and semiactive control integrated structural model for seismic vibration mitigation was numerically presented by Yanik and Aldemir [8]. For an active vibration isolation system, active hybrid control technology was applied in Wang et al. [9]. A mixed $\mathrm{H}_{2} /$ $H_{\text {infinity }}$-based active state feedback controller was described for mitigating vibrations in seismic excited container cranes in Azeloglu and Sagirli [10]. 
In addition to the control methods or control approaches defined above, one of the most popular active control algorithms is Linear Quadratic Regulator Control (LQR) $[11,12]$. However, there have been many criticisms on LQR controllers. It was stated by Yang et al. [13] that LQR controllers are known to be ineffective for systems suffering from variation of parameters and excitations which are broadband. In addition, it has been mentioned by Aldemir and Bakioglu [14] that only classical closed-loop control is applicable to structural control problems, and the Riccati equation is derived by not considering the seismic excitation term. It has been shown by Etedali and Tavakoli [15] that LQR did not show good performance in mitigating the seismic responses of an 11-story structure incorporating active tuned mass damper (ATMD) under strong seismic excitations. After comparing three active control methods with numerical examples that consist of buildings with different elevation including an ATMD on the top floor, it was obtained by Sareban [16] that, in LQR procedure, the applied force was limited. To overcome the deficiency of classical linear optimal control algorithms which are the applications of LQR $[11,17]$, instantaneous optimal control algorithms for active structural control were first introduced Yang et al. [18]. It has been stated in [18] that instantaneous optimal control laws were defined for providing feasible control algorithms that can easily be implemented for applications to seismic-excited structures. Combination of instantaneous optimal control and iterative learning control has been analytically proposed by Tong [19], and a 20-story shear building was taken into account for numerical verification of the method. An instantaneous control algorithm for magnetorheological damping, which considered relative acceleration and velocity feedback, was analytically defined and numerically verified by Chandiramani and Purohit [20].

An absolute instantaneous optimal control performance index is analytically defined in this study. In this method, absolute velocity and absolute displacements of the structure are fed into the conventional state vector to obtain the resulting control force. A shear building and a 3D tier building are taken into account to perform the dynamic analysis under unidirectional and bidirectional earthquake excitation. The uncontrolled response reduction performance under seismic excitation, of the proposed performance index is compared with LQR. The formulation of the problem is given in Section 2.

\section{Formulation of the Problem}

An $n$ story shear building with a fully active tendon controller system under the effect of unidirectional earthquake is schematically depicted in Figure 1. This structure's equation of the motion can be presented as

$$
\mathbf{M X}(t)+\mathbf{C X}(t)+\mathbf{K X}(t)=\mathbf{E} f(t)+\mathbf{L} \mathbf{U}(t),
$$

where $\mathbf{X}(t)=\left(X_{1}, X_{2}, \ldots, X_{n}\right)^{\mathrm{T}}$ is the vector representing the relative displacement of each story relative to the ground, the dimension of this vector is $n, \mathbf{M}$ is the mass matrix with the dimensions of $(n \times n)$. The elements of mass matrix is $m_{i}=$ mass of $i$ th story $(i=1,2, \ldots, n), \mathbf{C}$ and $\mathbf{K}$ are damping and stiffness matrices in a respective way, both $\mathbf{C}$ and $\mathbf{K}$ are $(n \times n)$ dimensional matrices, $\mathbf{E}(n \times 1)$ is the matrix related with the location of the excitation, and it can be written as $\mathbf{E}^{\mathrm{T}}=-\left(m_{1}, \ldots, m_{n}\right)$, active control location matrix is $\mathbf{L}$, the dimension is $(n \times r)$, where $r$ is the number of active controllers, $\mathbf{U}(t)$ is the force vector of active controllers and can be presented as $\mathbf{U}^{\mathrm{T}}(t)=\left(\mathrm{u}_{1}(t), \ldots, \mathrm{u}_{r}(t)\right)$, the dimension of $\mathbf{U}(t)$ is $r$ and $f(t)$ is a scalar which can be defined as the unidirectional earthquake acceleration. Initial displacement and the initial velocity of this structure can be presented as

$$
\begin{aligned}
& \mathbf{X}\left(t_{0}\right)=\mathbf{X}^{(0)} ; \\
& \dot{\mathbf{X}}\left(t_{0}\right)=\mathbf{X}^{(1)}
\end{aligned}
$$

If we define a conventional state vector as $\mathbf{Z}=(\mathbf{X}, \dot{\mathbf{X}})^{\mathrm{T}}$, the state space form of equation (1) can be written as

$$
\dot{\mathbf{Z}}(t)=\mathbf{A Z}(t)+\mathbf{B U}(t)+\mathbf{D} f(t), \quad t \in\left(t_{0}, t_{1}\right) .
$$

where $t_{0}(t=0)$ is the time when the earthquake starts and $t_{1}$ is the duration longer than that of earthquake. The system matrices in equation (3) can be defined as

$$
\begin{aligned}
& \mathbf{A}=\left[\begin{array}{cc}
0 & \mathbf{I} \\
-\mathbf{M}^{-1} \mathbf{K} & -\mathbf{M}^{-1} \mathbf{C}
\end{array}\right] ; \\
& \mathbf{B}=\left[\begin{array}{c}
0 \\
\mathbf{M}^{-1} \mathbf{L}
\end{array}\right] \\
& \mathbf{D}=\left[\begin{array}{c}
0 \\
-\eta
\end{array}\right]
\end{aligned}
$$

where $\mathbf{I}$ is the identity matrix and the dimension is $(n \times n)$ and $\eta=(1, \ldots, 1)^{\mathrm{T}}$ is a vector which is constant with the dimension of $n$. The system expression given by equation (3) can be presented by considering Equation (2) as follows:

$$
\mathbf{Z}\left(t_{0}\right)=\mathbf{Z}^{0}=\left[\begin{array}{l}
\mathbf{X}^{(0)} \\
\mathbf{X}^{(1)}
\end{array}\right] \text {. }
$$

To apply the active control force to the building, a control law should be chosen. In this paper, LQR is chosen for comparing the seismic effectiveness of the proposed instantaneous optimal control performance index. Section 2.1 includes information on LQR.

2.1. Linear Quadratic Regulator Control (LQR). In $L Q R$ control, the classical integral type quadratic performance index

$$
J=\int_{0}^{t_{1}}\left(\mathbf{Z}^{\mathrm{T}} \mathbf{Q}_{\mathrm{C}} \mathbf{Z}+\mathbf{U}^{\mathrm{T}} \mathbf{R}_{\mathrm{C}} \mathbf{U}\right) \mathrm{d} t
$$

is minimized and the optimal control force can be obtained as follows:

$$
\mathbf{U}(t)=-\frac{1}{2} \mathbf{R}_{\mathrm{C}}^{-1} \mathbf{B}^{\mathrm{T}} \mathbf{P}(t) \mathbf{Z}(t)
$$

where $\mathbf{P}$ is the solution of the following nonlinear matrix Riccati equation: 


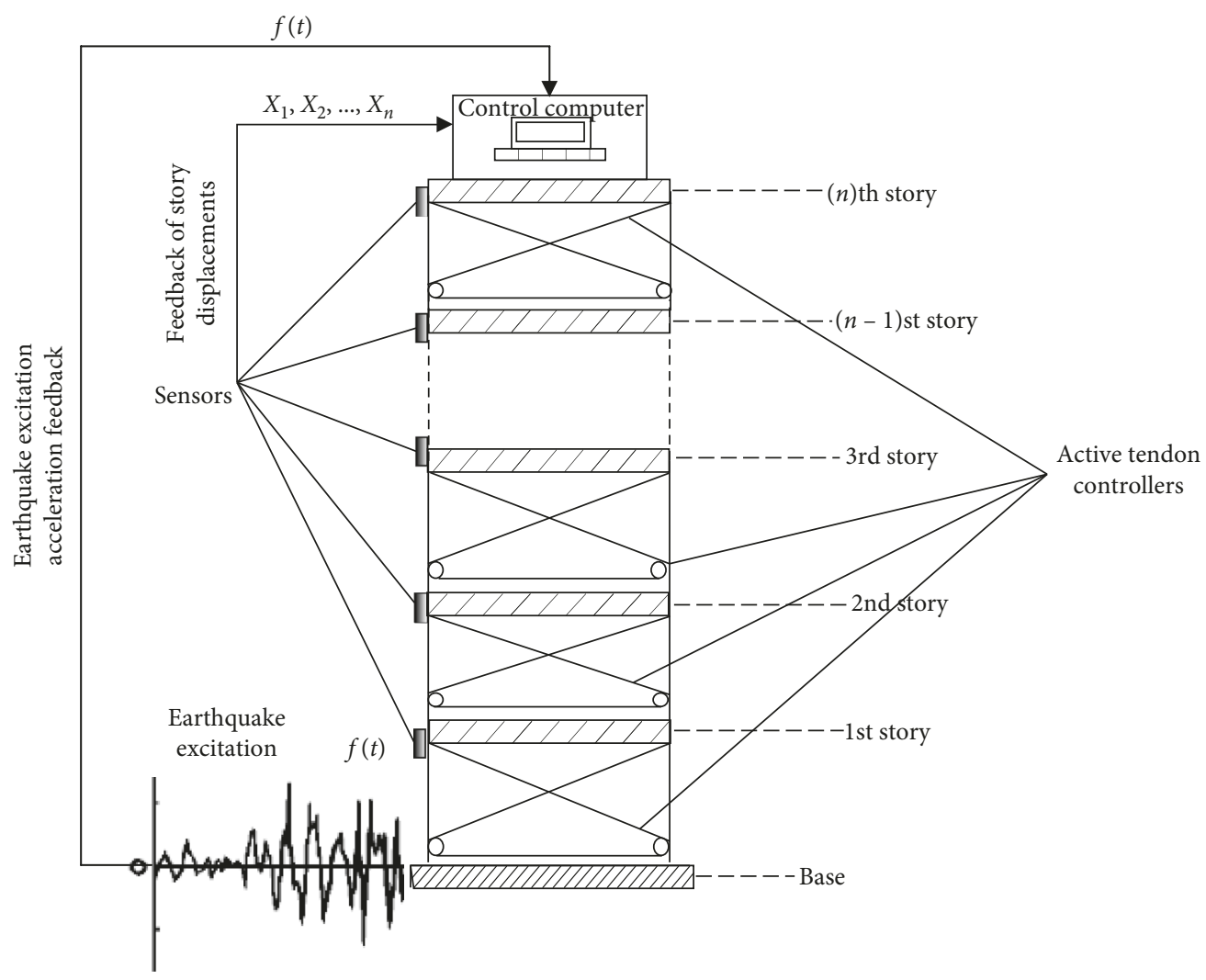

FIgURE 1: Example building with active tendon controllers.

$$
\dot{\mathbf{P}}(t)+\mathbf{P}(t) \mathbf{A}-\frac{1}{2} \mathbf{P}(t) \mathbf{B R}_{\mathrm{C}}^{-1} \mathbf{B}^{\mathrm{T}} \mathbf{P}(t)+\mathbf{A}^{\mathrm{T}} \mathbf{P}(t)+2 \mathbf{Q}_{\mathrm{C}}=0
$$

$$
\mathbf{P}\left(t_{1}\right)=0,
$$

where $\mathbf{Q}_{\mathrm{C}}$ and $\mathbf{R}_{\mathrm{C}}$ are the weighting matrices, $\mathbf{R}_{\mathrm{C}}$ is positive definite matrix, and $\mathbf{Q}_{\mathrm{C}}$ is a positive semidefinite matrix. The numerical values of these weighting matrices should be selected by considering the adjustment between the power requirement of the actuators and response reduction. Large values of the elements of $\mathbf{Q}_{C}$ matrix should be assigned if a significant structural response reduction is desired. In contrast, a designer should assign large values to $\mathbf{R}_{\mathrm{C}}$ weighting matrix if power consumption of the actuators is more important than the response reduction. We can also express equation (7) as

$$
\mathbf{U}(t)=\mathbf{G}_{\mathrm{C}} \mathbf{Z}(t)
$$

where $\mathbf{G}_{\mathrm{C}}(n \times 2 n)$ is the control gain and can be expressed as

$$
\mathbf{G}_{\mathrm{C}}(t)=-\frac{1}{2} \mathbf{R}_{\mathrm{C}}^{-1} \mathbf{B}^{\mathrm{T}} \mathbf{P}(t) .
$$

The Riccati matrix $\mathbf{P}(t)$ obtained from equation (8) does not yield an optimal solution since the excitation term $f(t)$ vanishes within the control interval $\left[0, t_{1}\right][21]$. The LQR formulation is given very briefly in this section. More information on $L Q R$ can be obtained from $[11,21]$. In Section 3 , the proposed performance index is defined.

\section{Absolute Instantaneous Optimal Control Performance Index}

An instantaneous optimal control performance index (INSABS) for active control is analytically presented in this section. This performance index uses absolute velocity and absolute displacement information as feedback in the state vector. It should be noted here that this performance index is another application of the instantaneous optimal control algorithms that were defined in the pioneering work of Yang et al. [18]. Therefore, there are some similarities between this study and the formulation defined in [18]. However, the big difference in this performance index is the absolute state vector implementation into the resulting index and eventually to the resulting control force expression. Before defining the performance index, the absolute state vector is defined as follows. The absolute accelerations for the given system can be written by using the parameters defined in equation (1) as

$$
\ddot{\mathbf{X}}_{\mathrm{abs}}(t)=\ddot{\mathbf{X}}(t)+\mathbf{v} f(t),
$$

where $\mathbf{v}$ is the $n$ dimensional location vector of earthquake excitation and can be written as $\mathbf{v}=\left[\begin{array}{lllll}1 & 1 & 1 & 1 & \ldots\end{array}\right]^{\mathrm{T}}$. The absolute velocities can be presented as

$$
\dot{\mathbf{X}}_{\mathrm{abs}}(t)=\dot{\mathbf{X}}(t)+\mathbf{v} \int_{t_{i}}^{t_{i+1}} f(t) \mathrm{d} t,
$$

where $\int_{t_{i}}^{t_{i+1}} f(t) \mathrm{d} t$ term is the velocity of the earthquake, $t_{i+1}-t_{i}=\Delta t$, and $\Delta t$ is the simulation time interval. The 
state vector considering absolute displacement and absolute velocity can be defined by modifying conventional state vector for each time interval as

$$
\mathbf{Z}_{\mathrm{abs}}(t)=[\mathbf{X}(t) \dot{\mathbf{X}}(t)]^{\mathrm{T}}+\left[\mathbf{v} \int_{t_{i}}^{t_{i+1}} \int_{t_{i}}^{t_{i+1}} f(t) \mathrm{d} t \mathbf{v} \int_{t_{i}}^{t_{i+1}} f(t) \mathrm{d} t\right]^{\mathrm{T}},
$$

where $\int_{t_{i}}^{t_{i+1}} \int_{t_{i}}^{t_{i+1}} f(t) \mathrm{d} t$ term is the displacement of the earthquake in each time interval. The time-dependent performance index considering absolute state vector can be stated as

$$
J_{\mathrm{abs}}(t)=\int_{0}^{\infty}\left[\mathbf{Z}_{\mathrm{abs}}^{\mathrm{T}}(t) \mathbf{Q} \mathbf{Z}_{\mathrm{abs}}(t)+\mathbf{U}^{\mathrm{T}}(t) \mathbf{R} \mathbf{U}(t)\right] \mathrm{d} t .
$$

By using backward difference approximation and implementing $\mathbf{Z}_{\mathrm{abs}}(t)$ into the state space expression given with equation (3), one can obtain the following equation:

$$
\begin{aligned}
\dot{\mathbf{Z}}_{\mathrm{abs}}(t)= & \mathbf{A}\left[\mathbf{Z}_{\mathrm{abs}}(t-\Delta t)+\Delta t \mathbf{Z}_{\mathrm{abs}}(t-\Delta t)\right]+\cdots \\
& +\mathbf{B} \mathbf{U}(t)+\mathbf{D} f(t) .
\end{aligned}
$$

The performance index $J_{\mathrm{abs}}(t)$ is minimized at each instant. The Hamiltonian of this instantaneous optimal control performance index $H$ can be expressed as

$$
\begin{aligned}
\mathbf{H}= & \dot{\mathbf{Z}}_{\mathrm{abs}}^{\mathrm{T}}(t) \mathbf{Q} \dot{\mathbf{Z}}_{\mathrm{abs}}(t)+\mathbf{U}^{\mathrm{T}}(t) \mathbf{R} \mathbf{U}(t)+\lambda^{T}\left\{\dot{\mathbf{Z}}_{\mathrm{abs}}(t)\right. \\
& \left.-\mathbf{A}\left[\mathbf{Z}_{\mathrm{abs}}(t-\Delta t)-\Delta t \dot{\mathbf{Z}}_{\mathrm{abs}}(t)-\mathbf{B} \mathbf{U}(t)+\mathbf{D} f(t)\right]\right\} .
\end{aligned}
$$

The necessary conditions for optimality are given below:

$$
\begin{aligned}
\frac{\partial \mathbf{H}}{\partial \dot{\mathbf{Z}}_{\mathrm{abs}}} & =0 ; \\
\frac{\partial \mathbf{H}}{\partial \mathbf{U}(t)} & =0 ; \\
\frac{\partial \mathbf{H}}{\partial \boldsymbol{\lambda}} & =0 .
\end{aligned}
$$

As shown above, taking the derivatives of equation (16) by $\dot{\mathbf{Z}}_{\text {abs }}, \mathbf{U}(t)$, and $\lambda$ gives the equations as follows, respectively,

$$
\begin{gathered}
2 \mathbf{Q} \dot{\mathbf{Z}}_{\mathrm{abs}}(t)+\lambda^{\mathrm{T}}=0, \\
2 \mathbf{R} \mathbf{U}(t)-\lambda(t) \mathbf{B}=0, \\
\dot{\mathbf{Z}}_{\mathrm{abs}}(t)-\mathbf{A}\left[\mathbf{Z}_{\mathrm{abs}}(t-\Delta t)-\Delta t \dot{\mathbf{Z}}_{\mathrm{abs}}(t-\Delta t)\right] \\
-\mathbf{B} \mathbf{U}(t)-\mathbf{D} f(t)=0,
\end{gathered}
$$

with necessary operations on equations (18) and (19), the resulting proposed active control force can be written as

$$
\mathbf{U}(t)=-\mathbf{R}^{-1} \mathbf{B}^{\mathrm{T}} \mathbf{Q} \dot{\mathbf{Z}}_{\mathrm{abs}}(t)
$$

The numerical examples are shown in Section 4.

\section{Numerical Examples}

In this section, firstly, the $2 \mathrm{D}$ shear building example is defined and the results obtained from dynamic simulations under earthquake excitation are given. For numerically verifying the proposed performance index in a more complex model, a tier building example is also presented. Tier buildings are simply three-dimensional shear buildings. Formulation of these buildings is presented in the appendix of this paper. More information on these buildings can be obtained in $[6,22,23]$. In a tier building, each story has three degrees of freedom. These degrees of freedom are one rotational degree of freedom and two degrees of freedoms for the orthogonal axes.

4.1. Shear Building Example. A shear building with active tendon controllers is considered for the numerical verification of the INS-ABS performance index as shown in Figure 2. The shear building is eight storied, and there are eight active tendon controllers in the building. The same example structure parameters given in Yang et al. [18] are used in this study. As this study is another simple application of instantaneous optimal control algorithms, the Yang et al. [18] model was chosen to be consistent with the first pioneering work on instantaneous controllers. The mass of each story of the structure is identical and chosen as $m=345.6$ tons, while the stiffness $k$ of each story is the same and $k=3.404 \times 10^{5} \mathrm{kN} / \mathrm{m}$ and the damping of each story is $c=2937$ tons $/ \mathrm{s}$. The frequencies of the building are obtained as $0.92,2.73,4.45,6.02,7.38,8.49,9.32$, and $9.82 \mathrm{~Hz}$. The frequencies of this model are calculated by solving the eigenvalue problem on the shear building. The active control weighting matrices $\mathbf{Q}_{C}$ and $\mathbf{R}_{C}$ for $L Q R$ and $\mathbf{Q}$ and $\mathbf{R}$ for INS-ABS are composed and given below [24]. There are 8 active tendon controllers in the building so that the size of $\mathbf{Q}$ matrix is 16 by 16 and $\mathbf{R}$ matrix is 8 by 8 . Researchers are still working on to develop a proper selection of weighting matrices. However, there are no exact rules or concrete methods on how to assign the numerical values to the elements of the weighting matrices. Therefore, within the framework of this paper, a case study is not carried out for the optimal selection of these weighting matrices. However, in this paper, $\mathbf{Q}_{\mathrm{C}}$ and $\mathbf{R}_{\mathrm{C}}$ for $\mathrm{LQR}$ and $\mathbf{Q}$ and $\mathbf{R}$ for INS-ABS are required to guarantee the stability of the controlled structure:

$$
\begin{aligned}
\mathbf{Q}_{\mathrm{C}} & =100\left[\begin{array}{cc}
\mathbf{K} & 0_{8 \times 8} \\
0_{8 \times 8} & \mathbf{M}
\end{array}\right] ; \\
\mathbf{Q} & =1000\left[\begin{array}{cc}
K & 0_{8 \times 8} \\
0_{8 \times 8} & \mathbf{M}
\end{array}\right], \\
\mathbf{R}_{\mathrm{C}} & =0.5 \times 10^{-2} \mathbf{I}_{8 \times 8}, \\
\mathbf{R} & =0.1 \times I_{8 \times 8} .
\end{aligned}
$$

The dynamic analysis is performed for 20 seconds with a fixed time step size of $0.01 \mathrm{~s}$. Matlab-Simulink are used to develop simulations. The seismic excitations used for the shear building are El Centro (1940), Erzincan (1992), and 


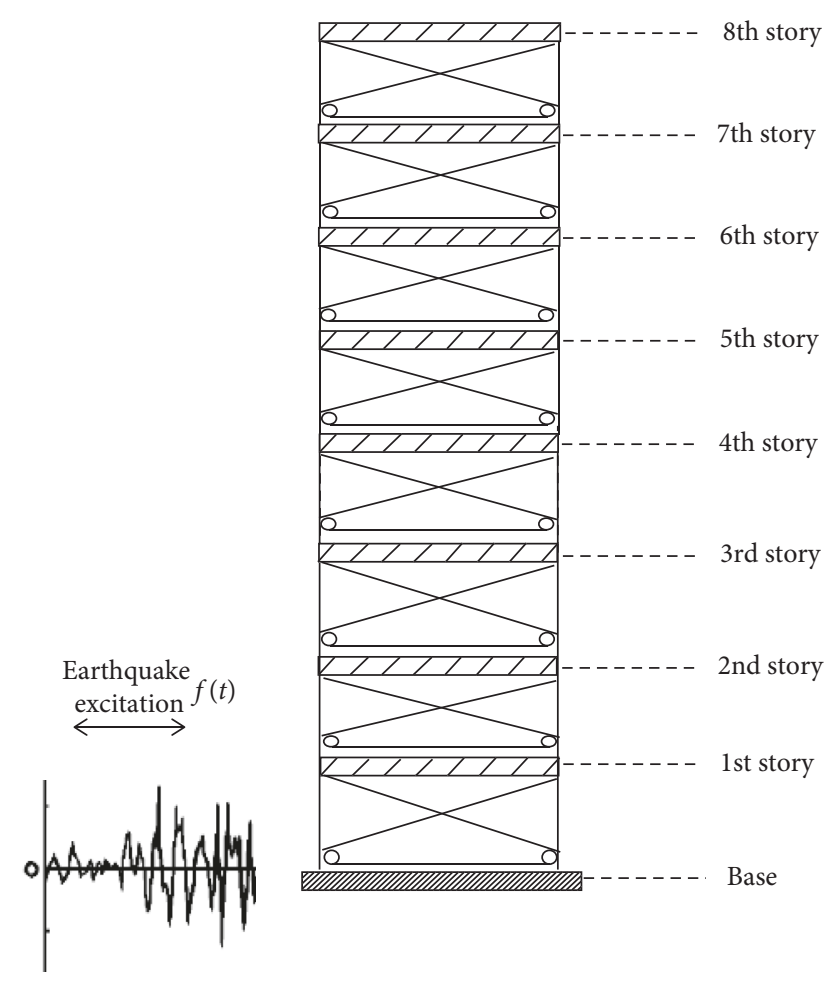

FIGURE 2: Eight-story shear building.

Northridge (1994) earthquakes. The ground motion parameters are shown in Table 1. These earthquake records are from the near fault regions of the corresponding earthquakes. With respect to the PGA information of these earthquakes, one moderate (El Centro) and two strong earthquakes are used in this study.

After running the simulations, time displacement and control force relationships as well as the maximum control energies of the structure are obtained. The top story time displacement and control force curve are shown in Figure 3 for El Centro earthquake. NC represents the uncontrolled conventional structure. Along with Figure 3, the displacement and absolute acceleration responses for all stories are defined with the following comparison measures:

$$
\begin{gathered}
P_{1}=\frac{\max \left|X_{i}\right|_{\substack{\mathrm{LOR} \\
\mathrm{INS}-\mathrm{ABS}}}}{\max \left|X_{1}\right|_{\mathrm{NC}}}, \\
P_{2}=\frac{\max \left|\ddot{X}_{\mathrm{abs}, i}\right|_{\mathrm{INS}-\mathrm{ABS}}}{\max \left|\ddot{X}_{\mathrm{abs}, 1}\right|_{\mathrm{NC}}}, \\
P_{3}=\frac{\max |\mathrm{CE}|_{\mathrm{INS}-\mathrm{ABS}}}{\max |\mathrm{CE}|_{\mathrm{LQR}}} .
\end{gathered}
$$

Comparison measures are calculated by normalizing the corresponding parameter with the uncontrolled first story displacement or absolute acceleration. Control energy (CE) is considered in the measures as well. Maximum absolute values of the corresponding parameters are taken into account in the calculation of the measures. The numerical values of the performance measures for El Centro earthquake are shown in Table 2.

As it can be indicated from Figure 3 and Table 2 that for El Centro earthquake, INS-ABS performance index is more effective in reducing uncontrolled absolute accelerations than LQR control algorithm with less control energy consumption. The reductions for structural displacements are at the same extent for both methods. The maximum displacement reduction percentages of different stories range from $10 \%$ to $47 \%$ for INS-ABS while they range from $14 \%$ to $48 \%$ for LQR. The reduction percentages for absolute accelerations are $39 \%$ to $56 \%$ for INS-ABS; however, these parameters range from $8 \%$ to $48 \%$ for LQR. The reductions of INS-ABS case are achieved with $12 \%$ less power consumption than LQR. The top story time displacement and control force curve is shown in Figure 4 for Northridge earthquake. The comparison measures are shown in Table 3 for the same earthquake.

It is shown in Figure 4 and Table 3 that under the effect of Northridge earthquake, INS-ABS performance index is more effective than LQR algorithm in reducing absolute accelerations with $5 \%$ less control energy. And, the uncontrolled displacement reduction percentages for both algorithms are at the same extent. Uncontrolled absolute acceleration response reduction percentages for different stories range from $49 \%$ to $35 \%$ for INS-ABS while the same parameters range from $12 \%$ to $35 \%$ for LQR. In addition, the uncontrolled story displacements range from $33 \%$ to $35 \%$ for LQR and $32 \%$ to $36 \%$ for INS-ABS. The same comparisons are carried out for Erzincan earthquake. The results are presented in Figure 5 and Table 4.

Like the two other earthquakes, INS-ABS is found to be more effective in reducing absolute accelerations than LQR with $19 \%$ less control energy consumption under the effect of Erzincan earthquake. The uncontrolled absolute acceleration reduction percentages range from $34 \%$ to $45 \%$ for INS-ABS performance index, while the same parameters range from $-1 \%$ to $34 \%$ for LQR. Moreover, the uncontrolled displacement reduction percentages are at the same extent for all earthquakes. 3D tier building example and simulation results are presented in Section 4.2.

4.2. Tier Building Example. As shown in the previous section, El Centro earthquake resulted in the smallest structural responses. Therefore, in this section, Erzincan and Northridge earthquakes are used in the simulations. The acceleration time histories of these earthquakes are shown in Figure 6. Faultnormal and fault-parallel components of these earthquakes are considered in the numerical simulations.

A six-story four-bay 2D building model is used for conversion to a 3D tier building model in this section. The six-story structure is assumed to be $50 \mathrm{~m}$ by $70 \mathrm{~m}$ in plan, and $27 \mathrm{~m}$ in elevation $(6 \times 4.5)$ as given in Figure 7. Each floor height is $4.5 \mathrm{~m}$. Mass of the first to fifth stories are 2000 tons and the sixth story is 10000 tons. The floor is composite construction that consists of concrete and steel. The columns 
TABLE 1: Earthquake records used in this study.

\begin{tabular}{|c|c|c|c|c|c|c|}
\hline Name of the earthquake & Year & Magnitude & Record station & PGA (g) & PGV $(\mathrm{cm} / \mathrm{s})$ & PGD $(\mathrm{cm})$ \\
\hline El Centro & 1940 & 7.1 & El Centro Terminal Substation & 0.35 & 33.45 & 7.4 \\
\hline Erzincan & 1992 & 6.69 & 95 Erzincan & 0.48 & 72.95 & 24.79 \\
\hline Northridge & 1994 & 6.69 & Rinaldi Receiving Station & 0.63 & 109.24 & 28.26 \\
\hline
\end{tabular}

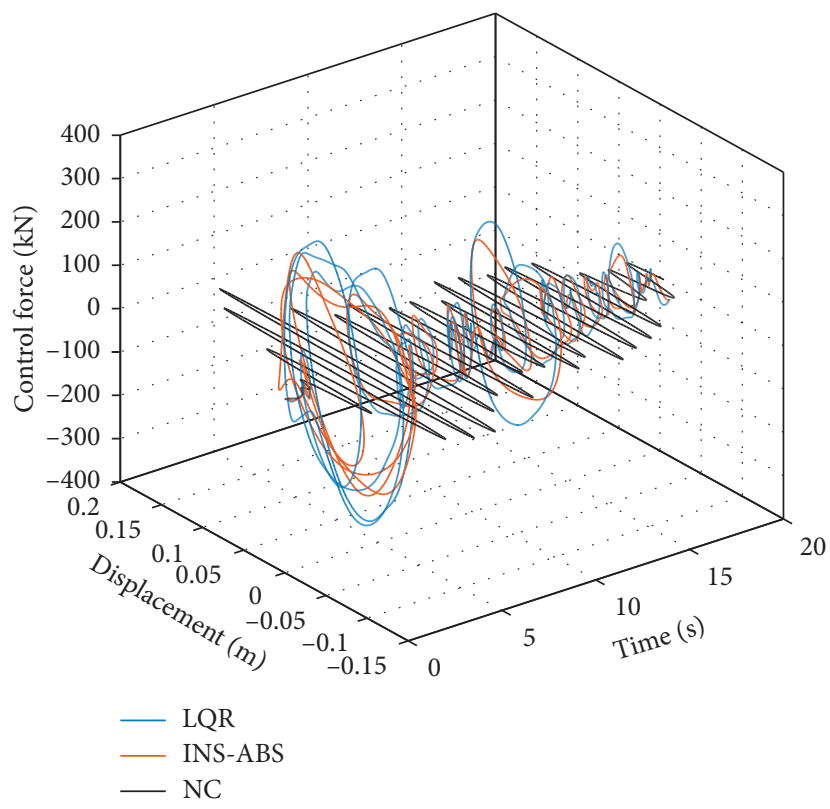

FIgUre 3: Top story displacement and control forces for El Centro earthquake.

TABLE 2: Comparison measures for El Centro earthquake.

\begin{tabular}{|c|c|c|c|c|c|c|c|c|}
\hline \multirow{2}{*}{ Story no } & \multicolumn{2}{|c|}{$\mathrm{NC}$} & \multicolumn{3}{|c|}{ LQR } & \multicolumn{3}{|c|}{ INS-ABS } \\
\hline & $P_{1}$ & $P_{2}$ & $P_{1}$ & $P_{2}$ & $P_{3}$ control energy & $P_{1}$ & $P_{2}$ & $\mathrm{P}_{3}$ control energy \\
\hline 1 & 1.00 & 1.00 & 0.86 & 0.92 & & 0.90 & 0.61 & \\
\hline 2 & 1.99 & 1.44 & 1.13 & 0.93 & & 1.21 & 0.73 & \\
\hline 3 & 2.93 & 1.58 & 1.64 & 1.05 & & 1.76 & 0.81 & \\
\hline 4 & 3.80 & 1.66 & 2.09 & 1.11 & & 2.20 & 0.88 & \\
\hline 5 & 4.55 & 1.80 & 2.46 & 1.12 & $1(1018))$ & 2.55 & 0.95 & $0.88(906))$ \\
\hline 6 & 5.16 & 2.10 & 2.74 & 1.14 & & 2.82 & 1.04 & \\
\hline 7 & 5.58 & 2.44 & 2.94 & 1.26 & & 3.00 & 1.12 & \\
\hline 8 & 5.81 & 2.66 & 3.04 & 1.36 & & 3.10 & 1.17 & \\
\hline
\end{tabular}

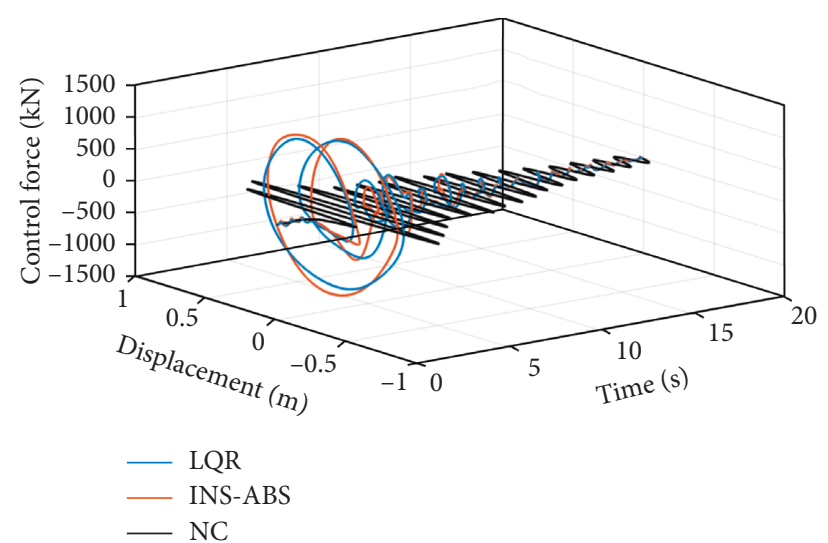

Figure 4: Top story displacement and control forces for Northridge earthquake. 
TABLE 3: Comparison measures for El Centro earthquake.

\begin{tabular}{|c|c|c|c|c|c|c|c|c|}
\hline \multirow{2}{*}{ Story no } & \multicolumn{2}{|c|}{$\mathrm{NC}$} & \multicolumn{3}{|c|}{ LQR } & \multicolumn{3}{|c|}{ INS-ABS } \\
\hline & $P_{1}$ & $P_{2}$ & $P_{1}$ & $P_{2}$ & $P_{3}$ control energy & $P_{1}$ & $P_{2}$ & $P_{3}$ control energy \\
\hline 1 & 1.00 & 1.00 & 0.65 & 0.88 & & 0.70 & 0.68 & \\
\hline 2 & 1.95 & 1.55 & 1.26 & 1.01 & & 1.29 & 0.82 & \\
\hline 3 & 2.82 & 1.96 & 1.82 & 1.27 & & 1.83 & 0.99 & \\
\hline 4 & 3.57 & 2.26 & 2.33 & 1.43 & & 2.29 & 1.20 & \\
\hline 5 & 4.19 & 2.38 & 2.76 & 1.68 & $1(14994))$ & 2.68 & 1.41 & $0.95(14317 \mathrm{~J})$ \\
\hline 6 & 4.66 & 2.48 & 3.11 & 1.85 & & 2.97 & 1.59 & \\
\hline 7 & 4.98 & 2.67 & 3.33 & 1.91 & & 3.18 & 1.72 & \\
\hline 8 & 5.14 & 2.80 & 3.45 & 1.92 & & 3.28 & 1.78 & \\
\hline
\end{tabular}

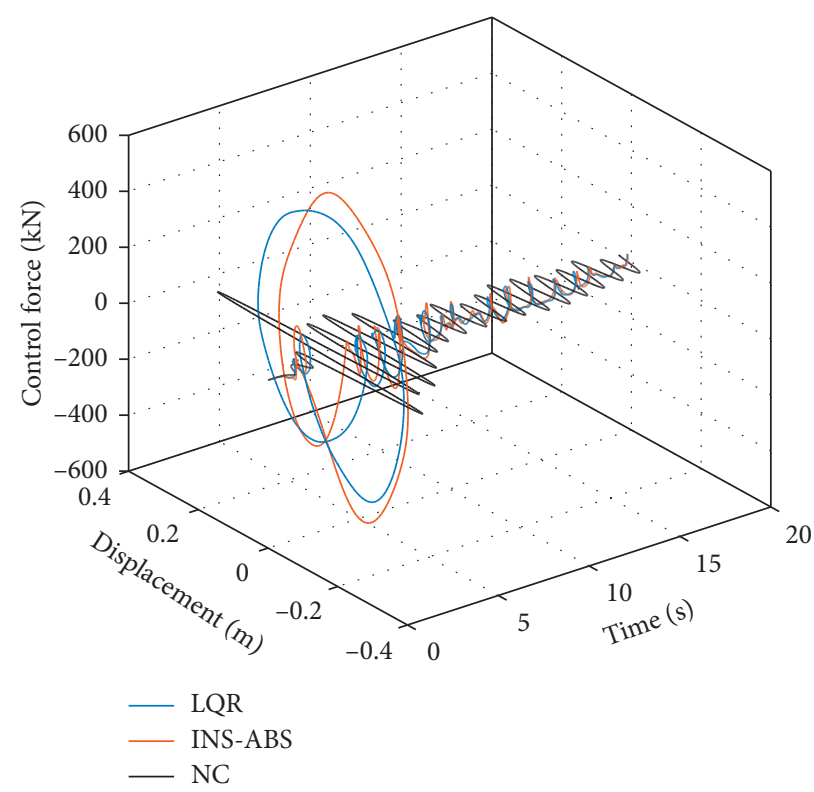

FIgURE 5: Top story displacement and control forces for Erzincane earthquake.

TABle 4: Comparison measures for Erzincan earthquake.

\begin{tabular}{|c|c|c|c|c|c|c|c|c|}
\hline \multirow{2}{*}{ Story No } & \multicolumn{2}{|c|}{$\mathrm{NC}$} & \multicolumn{3}{|c|}{ LQR } & \multicolumn{3}{|c|}{ INS-ABS } \\
\hline & $P_{1}$ & $P_{2}$ & $P_{1}$ & $P_{2}$ & $P_{3}$ control energy & $P_{1}$ & $P_{2}$ & $P_{3}$ control energy \\
\hline 1 & 1.00 & 1.00 & 0.67 & 1.01 & \multirow{8}{*}{$1(2718 \mathrm{~J})$} & 0.70 & 0.59 & \multirow{8}{*}{$0.89(2203 \mathrm{~J})$} \\
\hline 2 & 1.96 & 1.14 & 1.31 & 1.03 & & 1.40 & 0.76 & \\
\hline 3 & 2.84 & 1.55 & 1.88 & 1.13 & & 1.90 & 0.93 & \\
\hline 4 & 3.61 & 1.94 & 2.39 & 1.32 & & 2.41 & 1.07 & \\
\hline 5 & 4.24 & 2.19 & 2.80 & 1.45 & & 2.92 & 1.19 & \\
\hline 6 & 4.72 & 2.25 & 3.11 & 1.49 & & 3.14 & 1.28 & \\
\hline 7 & 5.04 & 2.29 & 3.32 & 1.64 & & 3.33 & 1.34 & \\
\hline 8 & 5.20 & 2.48 & 3.43 & 1.80 & & 3.44 & 1.37 & \\
\hline
\end{tabular}

are $345 \mathrm{MPa}$ steel. The floor system is comprised of $248 \mathrm{MPa}$ steel wide-flange beams acting compositely with the floor slab [25]. The six-story structure has a total of 18 degrees of freedom with two orthogonal axes and a single rotational degree of freedom in each story. The frequencies of the building are calculated as $0.70,1.04,2.35,2.54,3.76,4.53$, $6.30,6.73,7.67,8.53,8.54,9.35,11.38,12.67,15.26,21.21$, 25.82 , and $28.74 \mathrm{~Hz}$. These frequencies are also calculated by solving the eigenvalue problem relating to the stiffness and mass matrix of the tier building. The information on these matrices is given in the appendix of this paper.

Tier building formulation is used in converting the $2 \mathrm{D}$ building into a simple 3D building. More information on 3D tier buildings and information on $2 \mathrm{D}$ to $3 \mathrm{D}$ conversion procedure in detail can be found in $[6,22,23]$. These types of structural plans were studied for in-plane (2D) analysis of the benchmark structures in Ohtori et al. [25]. The weighting matrices for LQR and INS-ABS are selected as 

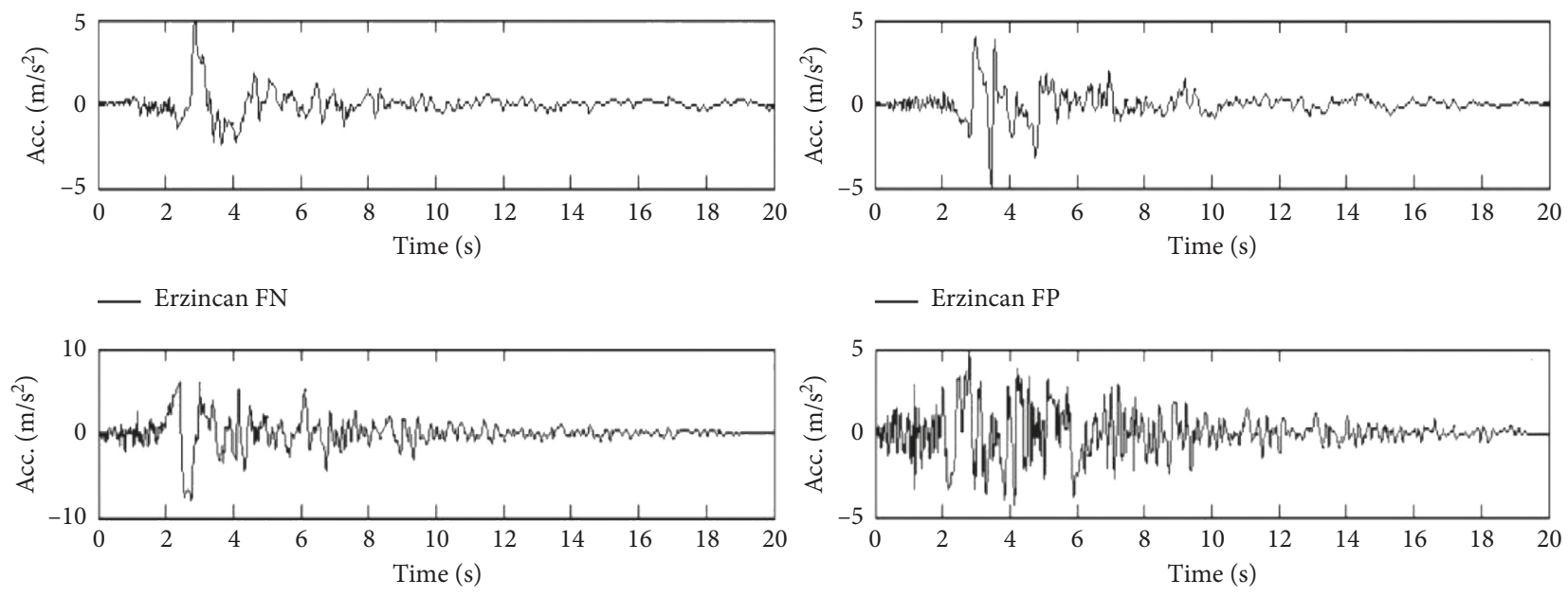

— Northridge FN

— Northridge FP

FIGURE 6: Fault normal and fault parallel components of the earthquake records.

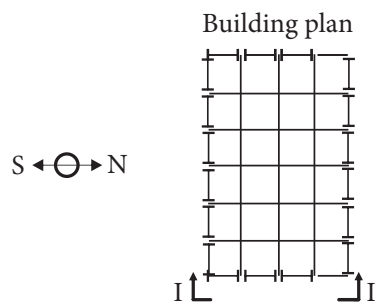

Elevation

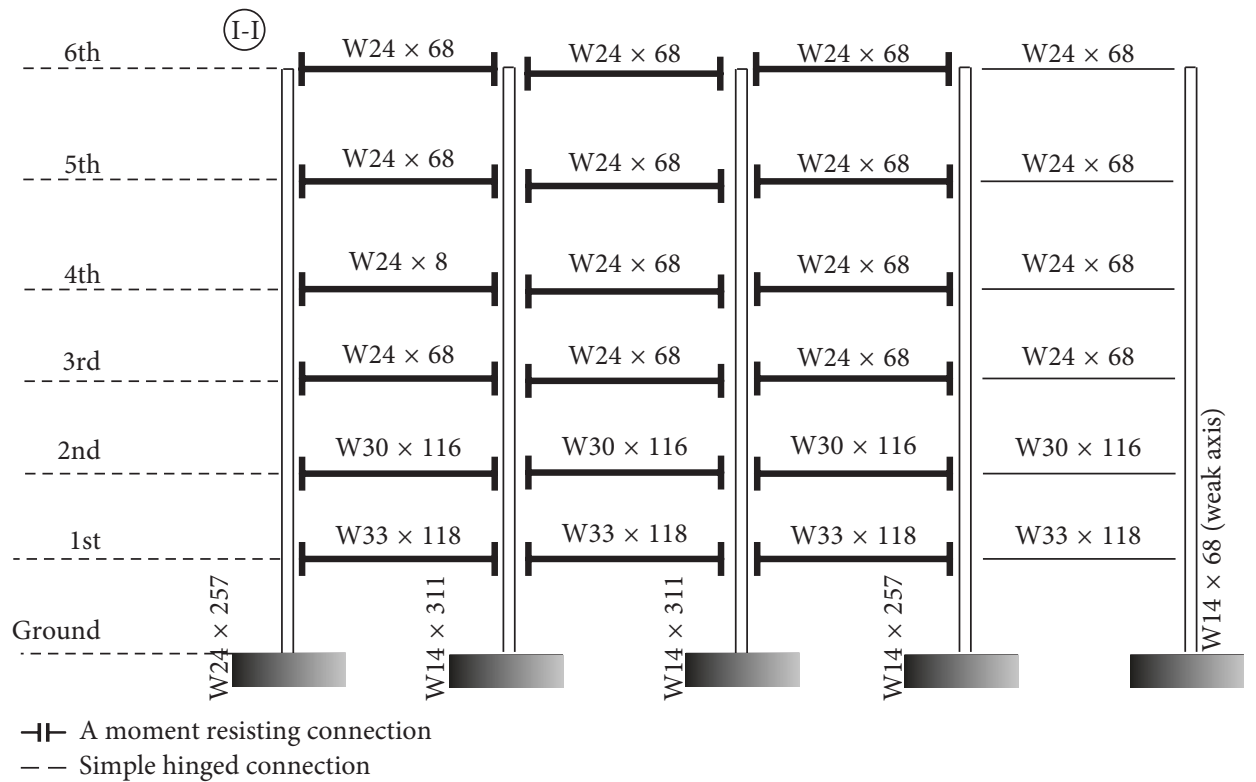

FIGURE 7: Six-story building structural plan.

$$
\begin{aligned}
\mathbf{Q}_{\mathrm{C}} & =40000\left[\begin{array}{ll}
\mathbf{K}_{3 d} & \mathbf{C}_{3 d} \\
\mathbf{C}_{3 d} & \mathbf{M}_{3 d}
\end{array}\right] ; \\
\mathbf{Q} & =10000\left[\begin{array}{ll}
\mathbf{K}_{3 d} & \mathbf{C}_{3 d} \\
\mathbf{C}_{3 d} & \mathbf{M}_{3 d}
\end{array}\right], \\
\mathbf{R}_{\mathrm{C}} & =\mathbf{I}_{6 \times 6}, \\
\mathbf{R} & =0.005 \mathrm{I}_{6 \times 6} .
\end{aligned}
$$

N-S direction is the direction where fault normal component of the earthquake acts. The maximum displacement in N-S direction and maximum rotation of each story for Erzincan bidirectional ground motion is shown in Figure 8. Tendon controllers are assumed to be operating in the N-S direction; therefore, both methods are not effective in reducing the displacements in E-W direction. It should be noted here that the displacements in E-W direction are almost three times smaller than the ones in N-S direction. It 


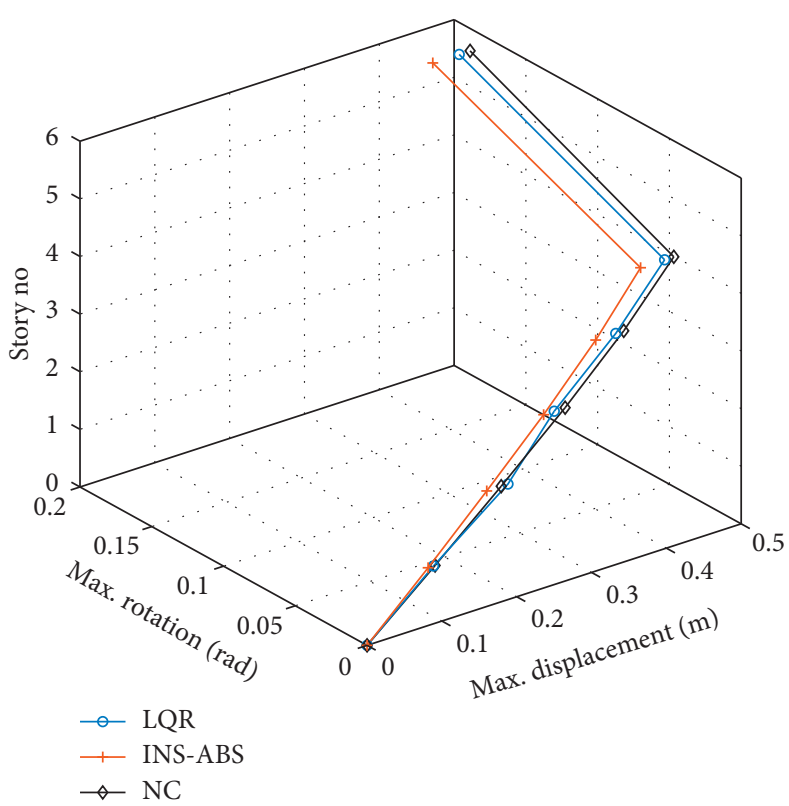

Figure 8: Maximum displacements and rotations for Erzincan bidirectional ground motion.

can be indicated from Figure 8 that the INS-ABS method is more effective than LQR in reducing both uncontrolled displacements and rotations. The uncontrolled N-S displacement reduction percentages range from $-5 \%$ (for the second story LQR resulted in bigger story displacement than NC) to $5.5 \%$ for LQR and from $10 \%$ to $11 \%$ for INS-ABS. These parameters for uncontrolled rotation range from $-0.63 \%$ to $2 \%$ for LQR and $11 \%$ to $15 \%$ for INS-ABS.

The maximum absolute accelerations in N-S direction and $\mathrm{E}-\mathrm{W}$ direction for each story are shown in Figure 9. As it is seen from Figure 9, LQR resulted in almost $37 \%$ to $2.54 \%$ bigger uncontrolled absolute accelerations in N-S direction. In $\mathrm{E}-\mathrm{W}$ direction, $\mathrm{LQR}$ control resulted in $7 \%$ to $18 \%$ bigger accelerations than NC. Only one-story acceleration is found to be smaller than NC in E-W direction. However, INS-ABS is obtained to be effective in absolute acceleration reduction. In N-S direction, uncontrolled absolute acceleration reduction percentages range from $7 \%$ to $18 \%$ for INS-ABS. These results are achieved with control energies that are at the same extent in both methods.

The same comparisons are carried out for the structure under Northridge bidirectional earthquake acceleration. Maximum displacements in N-S direction and rotations are shown in Figure 10 for this earthquake. It can be indicated from Figure 10 that maximum response reductions are achieved with INS-ABS. The uncontrolled displacement reduction percentages range from $4.8 \%$ to $8.5 \%$ for LQR. However, the same parameters range from $29 \%$ to $32 \%$ for the INS-ABS method. The rotations are at the same extent for LQR and NC. The uncontrolled rotation reduction percentages are around $14 \%$ for INS-ABS. The maximum absolute accelerations in N-S direction and $\mathrm{E}-\mathrm{W}$ direction for each story are shown in Figure 11.

It is shown in Figure 10 that LQR resulted in almost 6\% to $17 \%$ bigger uncontrolled absolute accelerations in N-S direction for some stories, and the absolute accelerations in

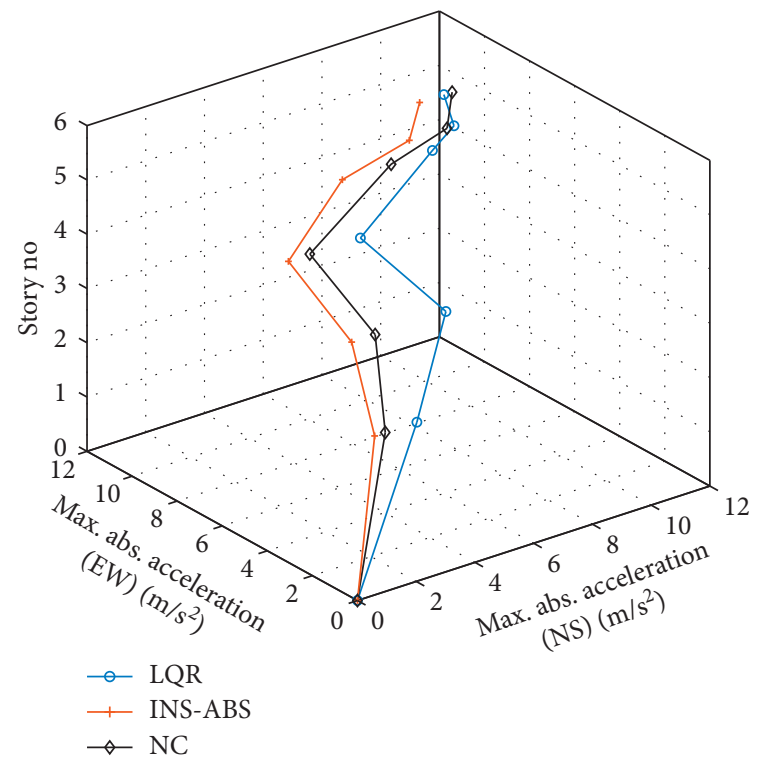

FIgURe 9: Maximum absolute accelerations in N-S and E-W directions for Erzincan bidirectional ground motion.

E-W direction are at the same extent with NC. However, INS-ABS case has smaller absolute accelerations than NC in N-S direction. For N-S direction, the uncontrolled absolute acceleration reduction percentages range from $14 \%$ to $34 \%$ in INS-ABS. The control energy consumption in INS-ABS case is found to be extremely smaller than LQR for Northridge earthquake. LQR resulted in almost 20 times bigger control energy than INS-ABS. The conclusions obtained from this study are given in Conclusions.

\section{Conclusions}

An absolute instantaneous optimal control performance index for seismically excited structures is analytically defined 


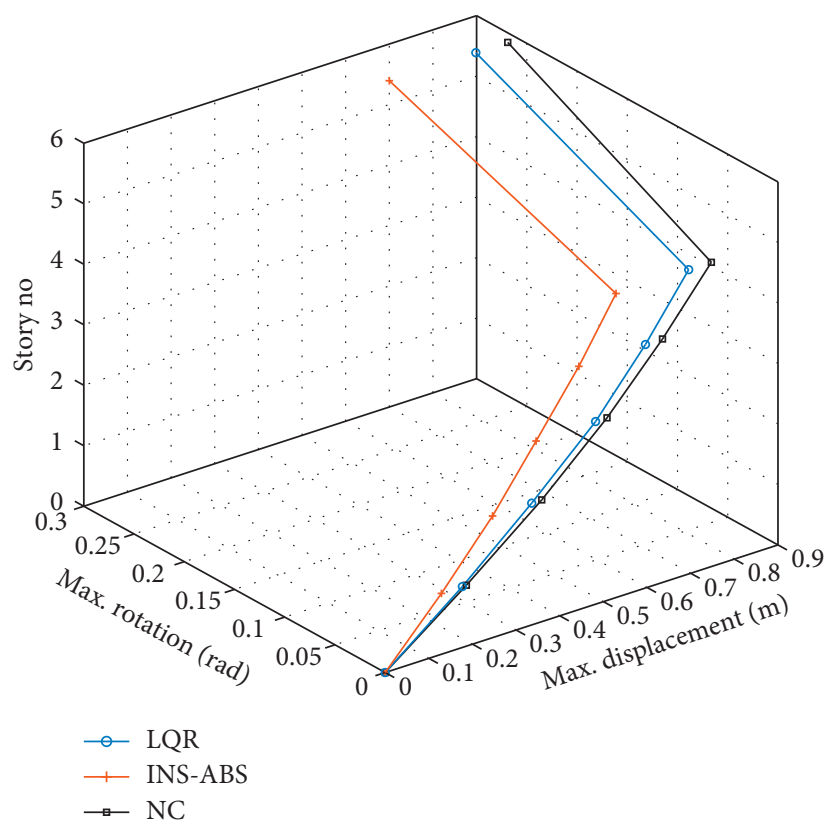

FIgURE 10: Maximum displacements and rotations for Northridge bidirectional ground motion.

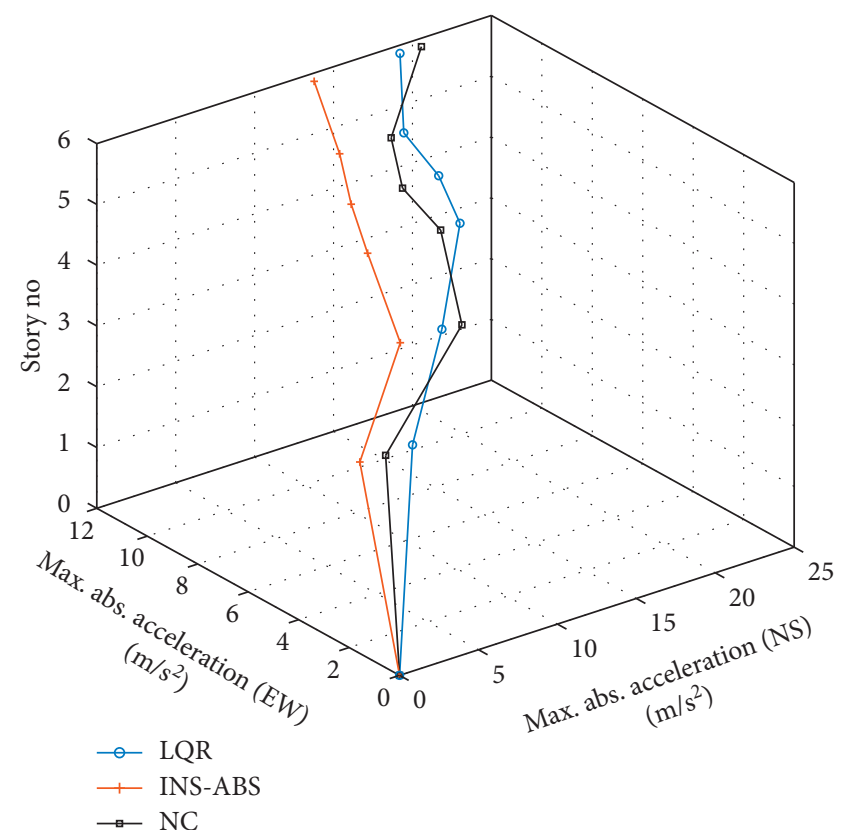

Figure 11: Maximum absolute accelerations in N-S and E-W directions for Erzincan bidirectional ground motion.

and numerically tested in this paper. The major distinction of this performance index from LQR is, as the nonlinear matrix Riccati equation of LQR is obtained by ignoring the earthquake excitation term, LQR is approximately optimal and does not satisfy the optimality condition. LQR cannot be applied to earthquake-excited structures, because the whole earthquake ground acceleration history is not known apriori. In comparison with the LQR, INS-ABS does not require a priori knowledge of the seismic excitation. Therefore, it can be applied to seismically excited structures. With respect to the numerical results, the proposed performance index reduces both the absolute accelerations and displacements of the uncontrolled structures. The numerical results also showed that for $3 \mathrm{D}$ tier buildings, INS-ABS performance index outperformed the LQR control algorithm in reducing both structural displacements and absolute accelerations in the fault normal direction of the earthquake. The structural rotations in INS-ABS case are also found to be smaller than LQR. In addition, it is obtained from shear building analysis that INS-ABS is more effective in reducing absolute accelerations than LQR with smaller control energy consumption. Control energy consumption is related with the power requirement of the active tendon controllers.

\section{Appendix}

In Figure 12, an $n$ story tier building with identical story height $(h)$ and floor lengths $\left(L_{x}\right.$ and $\left.L_{y}\right)$ in each story is simply given. CM and CS in Figure 12 represent the center of mass and center of stiffness. respectively. The control forces acting in NS direction are shown very simply with $U_{i}$. The displacements in NS and EW directions and rotation are given with $X_{i}, X_{i+1}$ and $\theta_{i}$ for the $i$ th story. Earthquake accelerations in NS and EW directions are denoted by $f_{x}(t)$ and $f_{y}(t)$, respectively. The mass and stiffness matrices for this building are shown below. 


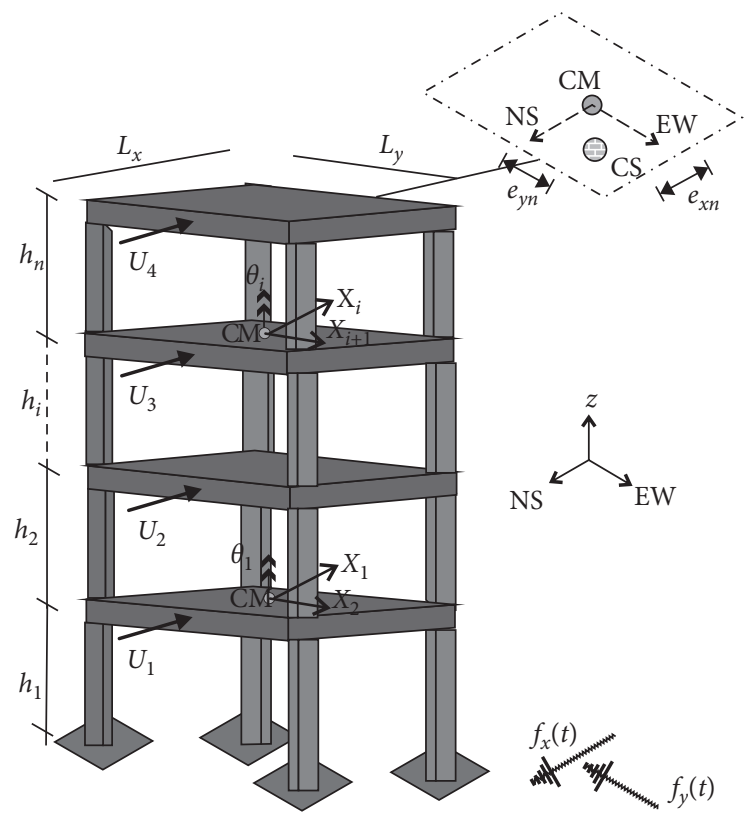

Figure 12: Simple tier building.

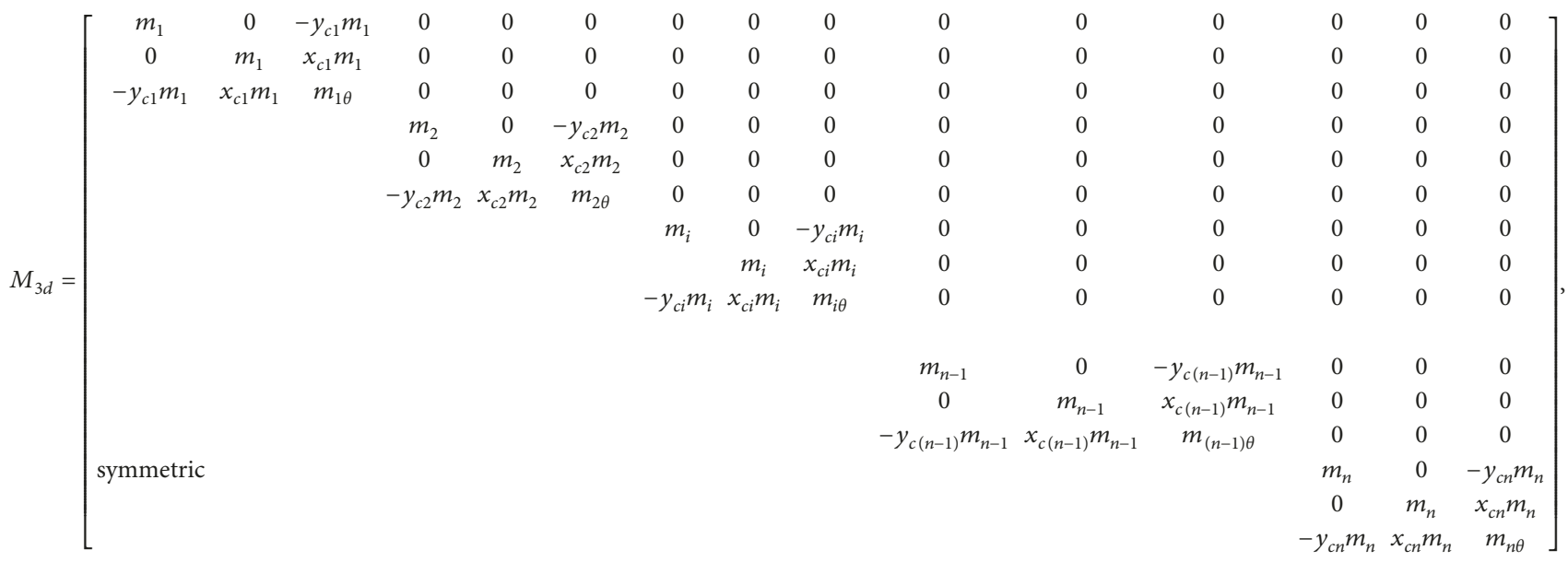

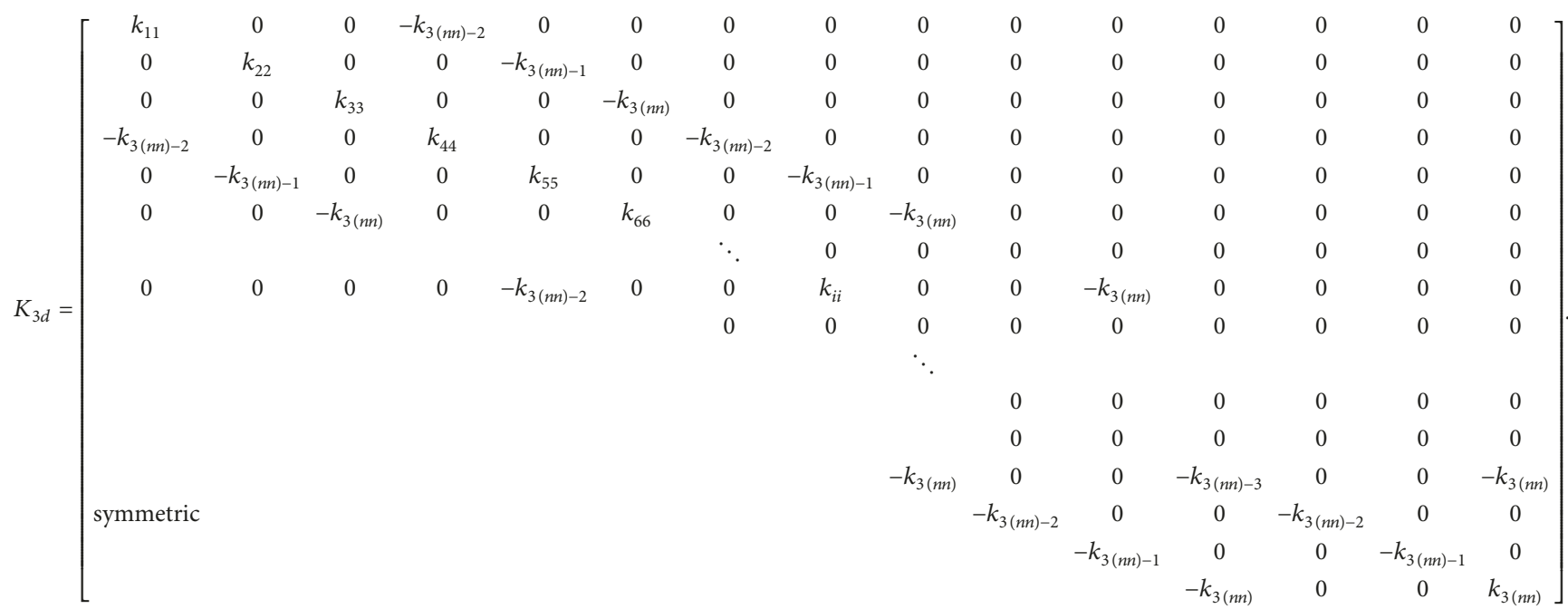


In the mass matrix, $m_{1}, m_{2}, m_{i}, m_{n-1}$, and $m_{n}$ are the mass of the first, second, $i$ th, $(n-1)$ th, and $n$th (top) story in a respective way. The eccentricities for first, second, $i$ th, $(n-1)$ th, and $n$th (top) story of the structure for NS and EW directions are given, respectively, as $x_{c 1}, y_{c 1}, x_{c 2}, y_{c 2}, x_{c i}, y_{c i}$, $x_{c(n-1)}, y_{c(n-1)}, x_{c n}$, and $y_{c n}$. The rotational masses for $n$ th, $(n-1)$ th, and $i$ th stories can be expressed as follows [6]:

$$
\begin{aligned}
m_{n \theta} & =m_{n \theta}\left(x_{c n}^{2}+y_{c n}^{2}+\rho_{n}^{2}\right) ; \\
m_{(n-1) \theta} & =m_{(n-1)}\left(x_{c(n-1)}^{2}+y_{c(n-1)}^{2}+\rho_{(n-1)}^{2}\right), \\
m_{i \theta} & =m_{i \theta}\left(x_{c i}^{2}+y_{c i}^{2}+\rho_{i}^{2}\right),
\end{aligned}
$$

where $\rho$ is the radius of gyration of the corresponding story. In the stiffness matrix, it is assumed that the moment of inertia of all stories is identical. Elasticity modulus $E$ is also assumed to be identical for all stories. The stiffness matrix components can be written as

$$
\begin{aligned}
k_{3(n n)-2} & =4 \times \frac{12 \mathrm{EI}_{1}}{h^{3}} ; \\
k_{3(n n)-1} & =4 \times \frac{12 \mathrm{EI}_{2}}{h^{3}} ; \\
k_{11} & =2 \times k_{3(n n)-2} ; \\
k_{22} & =2 \times k_{3(n n)-1}, \\
k_{33(n n)} & =2 \times L_{x}^{2}\left(\frac{12 \mathrm{EI}_{2}}{h^{3}}+\frac{12 \mathrm{EI}_{2}}{h^{3}}\right)+2 \times L_{y}^{2}\left(\frac{12 \mathrm{EI}_{1}}{h^{3}}+\frac{12 \mathrm{EI}_{1}}{h^{3}}\right), \\
k_{33} & =2 \times k_{3(n n)} ; \\
k_{i i} & =2 \times k_{3(n n)-2} ; \\
k_{3(n n)-3} & =2 \times k_{3(n n)} .
\end{aligned}
$$

In (A.4), $I_{1}$ and $I_{2}$ are the moment of inertias of the stories in NS and EW directions in a respective way.

\section{Data Availability}

The Matlab-Simulink simulations and data used to support the findings of this study are available from the author upon request.

\section{Conflicts of Interest}

The author declares that there are no conflicts of interest regarding the publication of this paper.

\section{Acknowledgments}

This work was partially supported by the Istanbul Technical University Research Fund (MAB-2018-41640).

\section{References}

[1] J. T. P. Yao, "Concept of structural control," Journal of the Structural Division, vol. 98, pp. 1567-1574, 1972.

[2] X. Shen, Y. Dai, M. Chen, L. Zhang, and L. Yu, "Active vibration control of the sting used in wind tunnel: comparison of three control algorithms," Shock and Vibration, vol. 2018, Article ID 1905049, 10 pages, 2018.

[3] J. E. Hughes, Y. Kim, J. W. Chong, and C. Kim, "Particle swarm optimization for active structural control of highway bridges subjected to impact loading," Shock and Vibration, vol. 2018, Article ID 4932870, 12 pages, 2018.

[4] R. Quintana and P. Diego, "A game-theoretical perspective for decentralized active noise control," Journal of Vibration and Control, vol. 24, no. 21, pp. 5062-5071, 2018.

[5] X. Wang and D. Yun, "Force feedback control method of active tuned mass damper," Shock and Vibration, vol. 2017, Article ID 9659425, 8 pages, 2017.

[6] A. Yanik, U. Aldemir, and M. Bakioglu, "A new active control performance index for vibration control of three-dimensional structures," Engineering Structures, vol. 62-63, pp. 53-64, 2014.

[7] K. Miyamoto, D. Sato, and J. She, “A new performance index of LQR for combination of passive base isolation and active structural control," Engineering Structures, vol. 157, pp. 280-299, 2018.

[8] A. Yanik and U. Aldemir, "A simple structural control model for earthquake excited structures," Engineering Structures, vol. 182, pp. 79-88, 2019.

[9] M. Wang, X. Li, and X. Chen, "Active hybrid control algorithm with sky-hook damping and lead-lag phase compensation for multi-DOFs ultra-low frequency active vibration isolation system," Shock and Vibration, vol. 2017, Article ID 1861809, 18 pages, 2017.

[10] C. O. Azeloglu and A. Sagirli, "Active vibration control of container cranes against earthquake by the use of LMI based mixed $\mathrm{H}$ 2/Ho state-feedback controller," Shock and Vibration, vol. 2015, Article ID 589289, 13 pages, 2015.

[11] T. T. Soong, Active Structural Control: Theory and Practice, John Wiley \& Sons, New York, NY, USA, 1990.

[12] S. N. Deshmukh and N. K. Chandiramani, "LQR control of wind excited benchmark building using variable stiffness tuned mass damper," Shock and Vibration, vol. 2014, Article ID 156523, 12 pages, 2014.

[13] S. M. Yang, C. J. Chen, and W. L. Huang, "Structural vibration suppression by a neural-network controller with a massdamper actuator," Journal of Vibration and Control, vol. 12, no. 5, pp. 495-508, 2006.

[14] U. Aldemir and M. Bakioglu, "Semiactive control of earthquake-excited structures," Turkish Journal of Engineering and Environmental Sciences, vol. 24, no. 4, pp. 237-246, 2000.

[15] S. Etedali and S. Tavakoli, "PD/PID controller design for seismic control of high-rise buildings using multi-objective optimization: a comparative study with LQR controller," Journal of Earthquake and Tsunami, vol. 11, no. 3, Article ID 1750009, 2017.

[16] M. Sareban, "Evaluation of three common algorithms for structure active control," Engineering, Technology \& Applied Science Research, vol. 7, no. 3, pp. 1638-1646, 2017.

[17] A. Sage and C. C. White III., Optimum Systems Control, Prentice-Hall, Englewood Cliffs, NJ, USA, 2nd edition, 1977.

[18] J. N. Yang, A. Akbarpour, and P. Ghaemmaghami, "New optimal control algorithms for structural control," Journal of Engineering Mechanics, vol. 113, no. 9, pp. 1369-1386, 1987. 
[19] S. W. Tong, "Optimal control using instantaneous optimal and iterative learning control," Sensors \& Transducers, vol. 179, no. 9, pp. 66-71, 2014.

[20] N. K. Chandiramani and S. P. Purohit, "Instantaneous optimal control of seismic response using magnetorheological damping," International Journal of Acoustics and Vibration, vol. 17, no. 1, pp. 4-13, 2012.

[21] H. Kwakernaak and R. Sivan, Linear Optimal Control Systems, Wiley, New York, NY, USA, 1972.

[22] W. Weaver Jr. and M. F. Nelson, "Three-dimensional analysis of tier buildings," Journal of the Structural Division, vol. 92, no. ST6, pp. 385-404, 1966.

[23] W. Weaver Jr., M. F. Nelson, and T. A. Manning, "Dynamics of tier buildings," Journal of the Structural Division, vol. 94, no. EM6, pp. 1455-1474, 1968.

[24] K. K. F. Wong and R. Yang, "Evaluation of response and energy in actively controlled structures," Earthquake Engineering \& Structural Dynamics, vol. 30, no. 10, pp. 1495-1510, 2001.

[25] Y. Ohtori, R. E. Christenson, B. F. Spencer Jr., and S. J. Dyke, "Benchmark control problems for seismically excited nonlinear buildings," Journal of Engineering Mechanics, vol. 130, no. 4, pp. 366-385, 2004. 


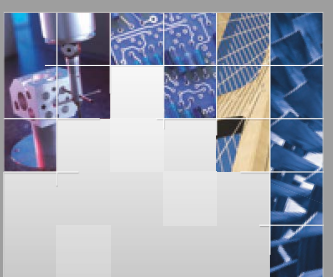

\section{Enfincering}
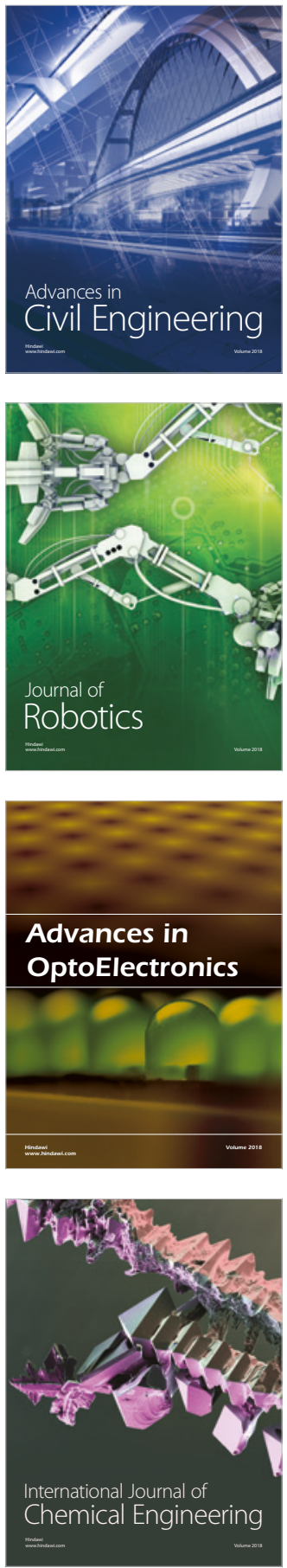

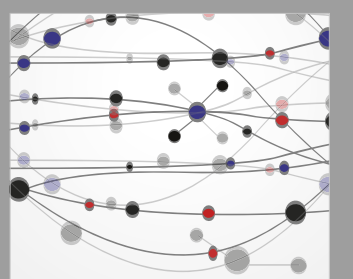

\section{Rotating \\ Machinery}

The Scientific World Journal

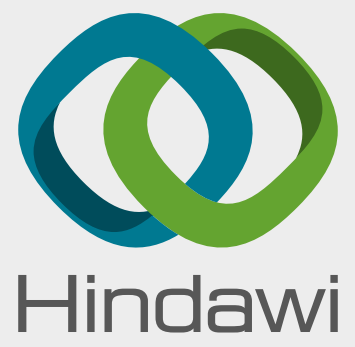

Submit your manuscripts at

www.hindawi.com
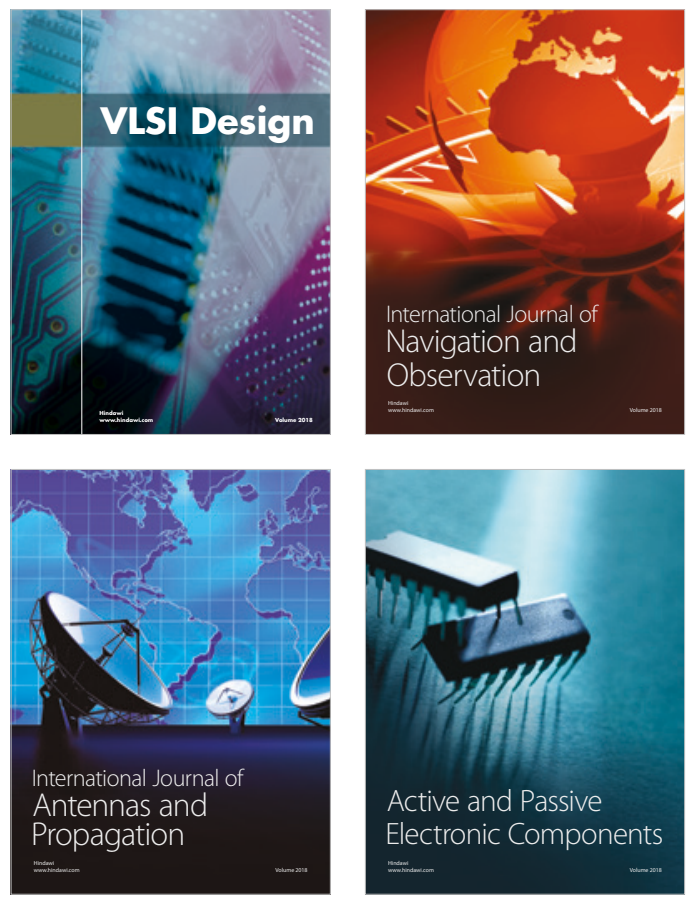
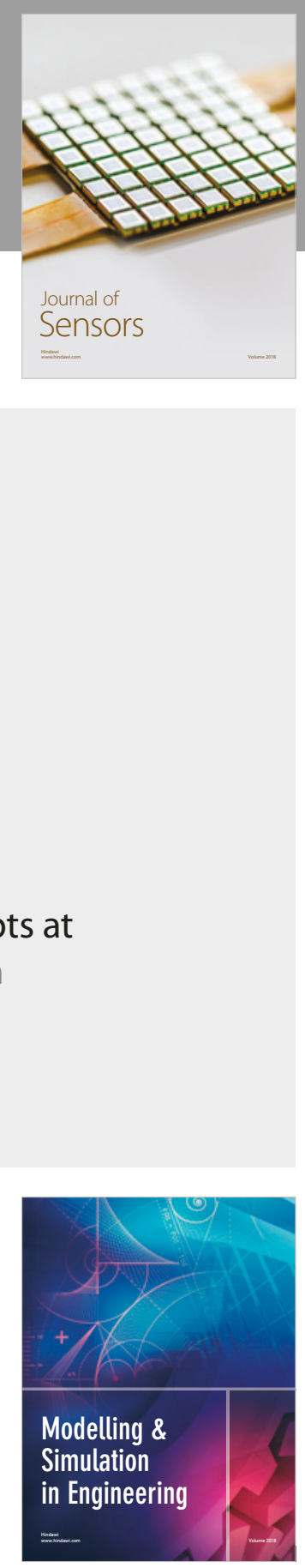

\section{Advances \\ Multimedia}
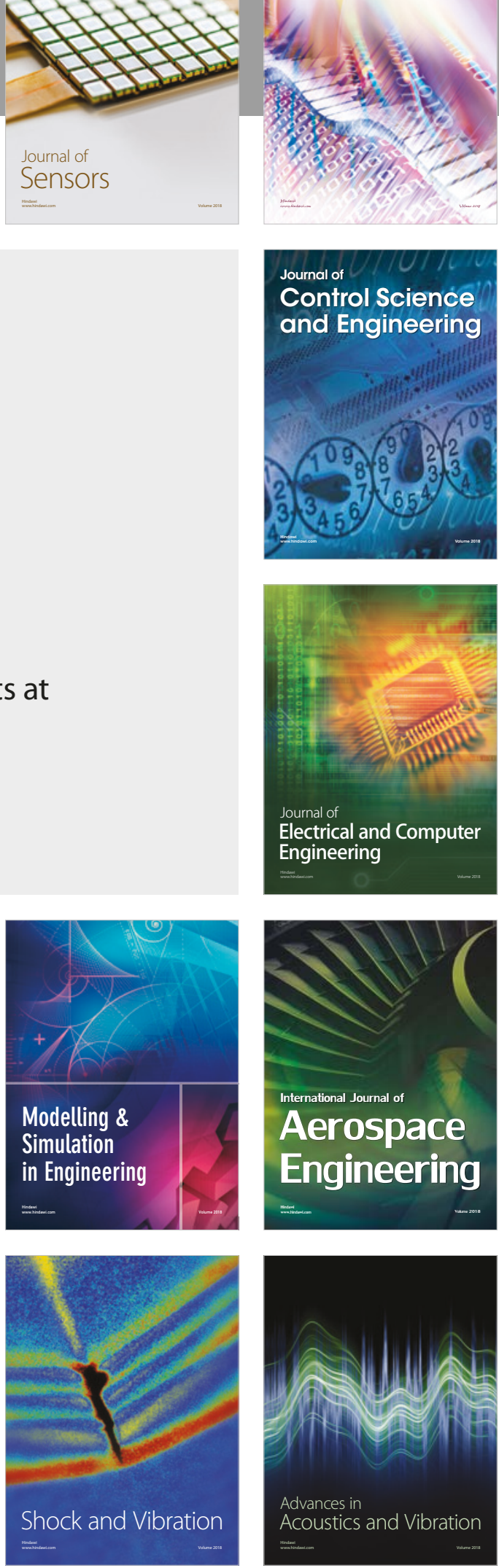